\title{
Usefulness of examining hepatic functional volume using technetium-99m galactosyl serum albumin scintigraphy in hepatocellular carcinoma
}

Nuclear Medicine Communications99mTc-GSA scintigraphy in HCC patients Nanashima et al.

Atsushi Nanashima1*, Takafumi Abo1, Takashi Kudo2, Ichiro Sakamoto3, Hideyuki Hayashi3, Goushi Murakami1, Hiroaki Takeshita1, Shigekazu Hidaka1, Yasuo Kido2, Takeshi Nagayasu1

${ }^{1}$ Division of Surgical Oncology and Department of Surgery

${ }^{2}$ Department of Radioisotope Medicine

${ }^{3}$ Department of Radiology,

Nagasaki University Graduate School of Biomedical Sciences, Nagasaki, Japan

${ }^{*}$ Correspondence to Atsushi Nanashima, MD, Department of Translational Medical Sciences,

Division of Surgical Oncology, Nagasaki University Graduate School of Biomedical Sciences, 1-

7-1 Sakamoto, Nagasaki 852-8501, JapanTel: +81 95819 7304; fax: +81 95819 7306; e-mail: a-

nanasm@nagasaki-u.ac.jp

$11 / 23 / 2012 ; 1 / 17 / 2013 ; 1 / 30 / 2013$

Objectives

The aim of the study was to clarify the clinical significance of single-photon emission computed tomography/computed tomography (SPECT/CT) imaging in terms of technetium-99m galactosyl human serum albumin ( ${ }^{99 \mathrm{~m}}$ Tc-GSA) scintigraphy. To this end, we examined the relationship using data from surgical records of 67 patients with hepatocellular carcinoma who underwent hepatectomy.

Materials and methods

Liver functional parameters or functional volume was estimated by ${ }^{99 \mathrm{~m}}$ Tc-GSA scintigraphy and computed tomography volumetry was used to estimate morphological volume.

Results

Liver uptake ratio at $15 \mathrm{~min}$ (LHL15) was correlated with the indocyanine green retention rate at 15 min (ICGR15; $R=-0.608, P<0.01$ ); however, five patients (7.5\%) had values outside this correlation. In these patients, LHL15 reflected clinical status and patient outcomes more. Although morphological and functional volumes were well correlated $(P<0.01)$, functional volume was decreased in the diseased liver with portal vein tumor thrombus or portal vein embolization. By applying ${ }^{99 \mathrm{~m}}$ Tc-GSA volumetry, portal pressure and alkaline phosphatase level were correlated with decreased volume of the embolized liver, and platelet count and cholesterol level were correlated with increased volume of the 
nonembolized liver $(P<0.05)$. By measuring functional volume, four patients who were functionally borderline on the basis of the ICGR15 test safely underwent scheduled major hepatectomy.

Conclusion

Under the ICGR15 test as the standard for preoperative hepatic function, auxiliary application of LHL15 and functional volumetry provides useful information on hepatocellular carcinoma patients undergoing hepatectomy.

Keywords:

diseased liver, functional liver volume, hepatocellular carcinoma, portal vein embolization, technetium99m galactosyl human serum albumin liver scintigraphy

\section{Introduction}

The incidence of postoperative hepatic failure in hepatocellular carcinoma (HCC) has markedly decreased in recent years following the introduction of adequate preoperative evaluation of hepatic function, estimation of resected liver volume, induction of preoperative portal vein embolization (PVE), and improvements in perioperative management (1-3). The Child-Pugh classification or indocyanine green (ICG) test is conventionally used to define the indications for safe hepatectomy (4). Makuuchi's criteria based on the serum level of total bilirubin, existence of ascites, and ICG retention rate at 15 min (ICGR15) for estimation of the extent of hepatectomy have often been applied in Japan and are suitable indicators for hepatectomy in primary or metastatic liver tumors $(4,5)$. However, when liver function of the hemiliver or segment is partially deteriorated because of decreased vascularization or biliary obstruction, these criteria are limited because of increased total bilirubin levels or poor ICG results. Further, segmental liver volume varies remarkably in some cases (6). Regardless of PVE, ICG test results are unimproved, even if the embolized hemiliver is remarkably diseased and functional volume is decreased (4). Thus, the conventional liver test does not reflect the diseased and healthy liver. In patients scheduled for resection, it is necessary to evaluate the remnant healthy liver segments. Liver scintigraphy has been used to evaluate the functional liver reserve, and evaluation of the separated liver area is possible using this method (7). Liver volume represents another piece of useful information to define operative indications and is usually measured by computed tomography (CT) (4-6,8-10). In cases of PVE, both the morphological liver volume and functional liver volume may change before and after embolization. Asialoglycoprotein receptors on hepatocytes reflect functional liver cells. $(11,12)$. Using scintigraphy, functional hepatic volume in the separated lobe of the liver can also be measured by applying single-photon emission computed tomography (SPECT) (11-16). As a result, technetium-99m 
galactosyl human serum albumin $\left({ }^{99 \mathrm{~m}} \mathrm{Tc}-\mathrm{GSA}\right)$ scintigraphy provides information about both liver function and the volume of the active liver and is useful in selecting the most appropriate hepatectomy. We have previously reported the clinical significance of measuring the liver uptake of ${ }^{99 \mathrm{~m}} \mathrm{Tc}-\mathrm{GSA}$ as a preoperative functional liver reserve test as well as its significance and application $(17,18)$. In the case of bile duct carcinoma, evaluation of functional liver volume in the remnant healthy liver was useful (19), and we hypothesized that functional volume shifts from the injured liver by biliary obstruction or PVE to counterparts much more than morphological liver volume.

In the case of HCC, we also hypothesize that examination of the liver uptake ratio of ${ }^{99 \mathrm{~m}} \mathrm{Tc}-\mathrm{GSA}$ or its functional volume is useful to evaluate the separated liver function, which can be used for deciding the extent of hepatectomy. In the present study, we examined the relationship between parameters of ${ }^{99 \mathrm{~m}} \mathrm{Tc}$-GSA liver scintigraphy and the ICG test, clinicosurgical data, or outcomes in 67 HCC patients for clinical application. Representative cases of HCC, in which measurement of functional liver volume was considered particularly useful in deciding operative indications, are shown.

\section{Materials and methods}

\section{Evaluation of liver function for hepatectomy}

The Child-Pugh classification was evaluated and only patients with Child-Pugh score A were selected for major hepatectomy. In our hospital, the permitted volume of liver to be resected is determined preoperatively on the basis of ICGR15 using Takasaki's formula (20). A dose of $0.5 \mathrm{mg}$ ICG/kg body weight was injected intravenously and ICGR15 was measured using a photopiece applied to the fingertip (Sumitomo Electric, Tokyo, Japan) without blood sampling (21). The estimated resected liver volume, excluding tumor volume, was measured by CT volumetry $(4,5)$. Essentially, planned hepatectomy was performed if the permitted resected volume of the liver was greater than the estimated resected volume of the liver. When the permitted resected volume was less than the estimated volume, preoperative PVE was performed according to our criterion $(17,18)$. Functional liver volume was

estimated by ${ }^{99 \mathrm{~m}}$ Tc-GSA scintigraphy in six patients undergoing preoperative PVE. Liver uptake ratio at 15 min (LHL15) by ${ }^{99 m}$ Tc-GSA scintigraphy, as well as serum hyaluronic acid level, was also examined preoperatively, along with ICGR15 and other functional liver parameters (21,22). LHL15 was calculated from the dynamic image and defined as the ratio of uptake by the liver alone to that of uptake by the liver and heart at $15 \mathrm{~min}$ (23). The regions of interest (ROIs) that surround the liver and the heart were identified on the dynamic planar image. On the basis of previous studies, LHL15 greater than 0.85, serum total bilirubin level lower than $1.5 \mathrm{mg} / \mathrm{dl}$ (except in the case of Dubin-Johnson's syndrome (24)), serum hyaluronic acid level lower than $250 \mathrm{ng} / \mathrm{ml}$, and prothrombin activity greater than $70 \%$ were 
indications for major hepatectomy. When no correlation between ICGR15 and LHL15 was observed, preference was given to the results of LHL15, as of 2004 when our strategy for the indication of hepatectomy was established (25).

\section{Volumetric measurement by CT and ${ }^{99 \mathrm{~m}}$ Tc-GSA liver scintigraphy}

Morphological volume was measured using contrast-enhanced CT. For imaging of CT volumetry, serial transverse scans at 0.5-mm thickness with 0.4-mm intervals were taken using a 64-row multidetector CT system (Aquilion 64; Toshiba Medical Systems Co., Tokyo, Japan) and the resulting images were stored. Using workstation software (Ziostation System 1000, version 1.31; Ziosoft Inc., Tokyo, Japan), actual areas without tumors and large vessels in the liver area were traced and measured. Hepatic CT volume for each sector was then measured three dimensionally. Hepatic volume of each hemiliver was then measured by summation of the areas in each slice. For SPECT/CT imaging of functional volumetry, all patients received $3 \mathrm{mg}$ (185 MBq) of ${ }^{99 \mathrm{~m}}$ Tc-GSA (Nihon Medi-Physics, Nishinomiya, Japan) as a bolus dose through an antecubital vein. Images were obtained using an integrated SPECT/CT system with a large field-of-view gamma camera (Symbia T; Siemens AG, Malvern, Pennsylvania, USA) equipped with a high-resolution, parallel-hole collimator centered on the liver and precordium. Sequential abdominal digital images $(128 \times 128$ matrix) were acquired using an online nuclear data processor (Symbia T Series Processing Workplace; Siemens Medical Solutions USA Inc., Hoffman Estates, Illinois, USA) at 30 s/frame for the first 20 min after injection. Hepatic SPECT/CT images were acquired after a dynamic study $(26,27)$. Each set of projection data was obtained in a $128 \times 128$ matrix, and 60 projections (6\%step, 20 s/projection) were acquired. Transaxial SPECT images were reconstructed with 4.8-mm slice thickness. After SPECT image acquisition, CT image acquisition was performed using the same SPECT/CT scanner. Attenuation correction was applied on SPECT images using these CT data. Finally, CT and ${ }^{99 \mathrm{~m}} \mathrm{Tc}-\mathrm{GSA}$ SPECT fusion images were obtained and the functional volume in each sector was determined. To determine the surface boundary of regions of interest (ROIs), a cutoff level was set at $26 \%$ of the maximum counts of the liver, as the result closest to the actual volume was obtained in a phantom study (not published). The boundary of the ROI between adjacent sectors was determined manually on the basis of simultaneous CT images obtained by the radiologist (coauthor, TK). Hepatic volume was measured in each of the four sectors that is, the lateral, median, anterior, and posterior segments (Fig. 1).

\section{Technique of portal vein embolization and evaluation}

The approach to the right portal vein was direct catheterization of percutaneous transhepatic puncture $(18,21)$. Substances used for embolization comprised a mixture of $0.6 \mathrm{~g}$ of gelatin pieces 
(Spongel; Astellas Pharma, Tokyo, Japan) and 1 g of 5\% ethanolamine oleate iopamidol (Oldamin; Takeda Pharma, Osaka, Japan). Permanent embolization materials were not used. Embolization was completed when the entire right portal vein was completely occluded. Fourteen days after PVE, hepatic volumes of the unembolized liver and embolized liver (liver to be resected) were reassessed by CT volumetry, and liver function was also reassessed by ${ }^{99 m}$ Tc-GSA scintigraphy $(18,21,28)$. Surgical resection of the liver was performed 21 days after PVE.

\section{Statistical analysis}

All continuous data are expressed as mean \pm SD. Differences were examined using one-way analysis of variance and Student's $t$-test. Correlations between the two parameters were examined by calculating Pearson's correlation coefficient. A two-tailed value of $P$ lower than 0.05 was considered significant. SPSS for Windows version 18.0 (SPSS, an IBM Company, Chicago, Illinois, USA) was used for all statistical analyses.

\section{Results}

\section{Patient demographics}

The mean patient age was $69 \pm 10$ years (ranging from 38 to 84 years); there were 51 men and 16 women. The background liver was normal in four patients, whereas fatty liver was observed in one patient, chronic viral hepatitis in 50, and cirrhosis in 12. Thirty-five patients had hepatitis B, 24 had hepatitis C, and three had both. Hepatectomy consisted of partial resection in nine patients, segmentectomy or sectionectomy in 31, resection of segments 4 , 5, and 8 in three, hemihepatectomy in 18, and extended hemihepatectomy or trisectionectomy in six patients. With respect to preoperative liver functional parameters, mean ICGR15 was 15.9 $\pm 9.8 \%$ (ranging between 4 and 41\%) and mean LHL15 was $0.94 \pm 0.038$ (ranging between 0.76 and 0.96 ). The Child-Pugh classification was A in 63 patients and B in four. Liver damage grade was A in 53 patients and B in 14. Mean morphological liver volume was $707 \pm 162 \mathrm{~cm}^{3}$ (62 $\pm 9 \%$ ) [ranging from 4 to $1101 \mathrm{~cm}^{3}$ (4-98\%)] in the right lobe of the liver and $434 \pm 137 \mathrm{~cm}^{3}$ (38 $\pm 9 \%$ ) [ranging from 227 to $1090 \mathrm{~cm}^{3}$ (22-68\%)] in the left lobe of the liver. Mean functional liver volume was $631 \pm 254 \mathrm{~cm}^{3}$ (60 $\left.19 \%\right)$ [ranging from 6 to $1139 \mathrm{~cm}^{3}$ (4-98\%)] in the right and $450 \pm 191 \mathrm{~cm}^{3}$ (40 $16 \%$ ) [ranging from 90 to $986 \mathrm{~cm}^{3}$ (9-89\%)] in the left. Postoperative hepatic complications included hepatic failure in three patients, uncontrolled ascites in 11, and intra-abdominal infection in three.

Correlation between ICGR15 and LHL15 in HCC patients 
LHL15 was negatively correlated with ICGR15 (correlation coefficient, $R=-0.608$, $P<0.01$ ) in the present series (Fig. 2). Five of 67 HCC patients (7.5\%) had values outside the $95 \%$ confidence interval of this correlation. The demographics of these five patients are shown in Table 1. The first two cases showed better LHL15 in comparison with ICGR15. One showed an intractable liver abscess formation after radiofrequency ablation and additional TACE. In this case, uptake of ${ }^{99 \mathrm{~m}} \mathrm{Tc}-\mathrm{GSA}$ in the abscess formation of the right lobe of the liver was significantly decreased and that in the remnant liver was high (Fig. 3a). Right hepatectomy was scheduled and the patient outcome was uneventful. Histological findings showed no severe fibrosis or necroinflammatory response. In case 2, a large-sized HCC (>10 cm) occupied the right lobe of the liver and trisectionectomy was performed. Transient hyperbilirubinemia was observed but immediately improved within 10 days. The last three cases showed worse LHL15 in comparison with ICGR15. Case 3 showed remarkable atrophy of the right lobe of the liver after frequent transarterial chemoembolization for HCC. In this case, uptake of ${ }^{99 \mathrm{~m}} \mathrm{Tc}-\mathrm{GSA}$ in the right lobe of the liver was significantly decreased and atrophic and that in the left lobe of the liver was not high (Fig. 3b). Right hepatectomy was performed without blood transfusion; however, the patient had hypoxic encephalopathy due to hyperglycemia, and hepatic failure was subsequently observed. Histological findings showed precirrhosis. The last two patients underwent limited resection because of liver cirrhosis but long-term ascites were observed. We examined the postoperative complications between the former period (1994-2003, the period applying only ICGR15-based strategy) and the latter period (since 2004, applying the modified strategy) in all HCC patients who had undergone hepatectomy. In comparison with the former period, total hepatectomy-associated complications tended to be reduced [44/106 (42\%) and 28/98 (25\%), respectively; $P=0.074]$. In comparison with the former period, hepatic failure was not significantly decreased [7/106 (7\%) and 3/98 (3\%), respectively; $P=0.40]$. In comparison with the former period, uncontrolled ascites was significantly reduced [29/106 (42\%) and 14/98 (14\%), respectively; $P=0.034]$. Figure 4 shows the relationship between LHL15, extent of hepatectomy, and postoperative complications. Prevalence of uncontrolled ascites and hepatic failure were significantly increased according to the extent of hepatectomy $(P<0.05)$. However, the distribution of postoperative complications was not correlated with LHL15 ( $P=0.67)$. 
Correlation between morphological and functional volume in each liver area

Morphological hepatic volume in the right and left lobes of the liver was $682 \pm 267 \mathrm{~cm}^{3}$

(61.6 $\pm 19.7 \%)$ and $443 \pm 140 \mathrm{~cm}^{3}$ (38.4 $\left.\pm 19.7 \%\right)$, respectively. Functional hepatic volume in the right and left lobes of the liver was $641 \pm 262 \mathrm{~cm}^{3}(59.8 \pm 15.7 \%)$ and $469 \pm 190 \mathrm{~cm}^{3}(40.2 \pm 15.7 \%)$, respectively. There was no significant difference between morphological and functional hepatic volumes (Table 2). Figure 5 shows the positive correlations between morphological and functional hepatic volumes in each hemiliver $(P<0.01)$. The correlation between both hepatic volumes of the right lobe of the liver in HCC with major portal vein tumor thrombus was not significant $\left[648 \pm 132 \mathrm{~cm}^{3}(56.3 \pm 11.1 \%)\right.$ in morphology and $579 \pm 61 \mathrm{~cm}^{3}(50.5 \pm 18.7 \%)$ in RI volume, respectively]. Figure 6a shows a representative case of HCC located in segment 5, involving the right main portal vein. Morphological volume ratio in the left and right lobes of the liver was 37 and 63\%, respectively. The functional ratio in each lobe of the liver was 51 and 49\%, respectively. Functional volumes in the right lobe of the liver were decreased in comparison with morphological volume. Figure 6b shows results for a 58-year-old patient with HCC in the right lobe of the liver who underwent PVE because the permitted resected volume by ICGR15 was 63.9\%. After PVE, uptake of the left hemiliver did not increase. Further, hepatic functional reserve gradually worsened and hypersplenism due to increased portal hypertension was observed. Eventually, this patient did not undergo right hepatectomy.

Table 3 shows the correlation between preoperative hepatic parameters and volumetric changes after PVE. With regard to morphological changes, only the alkaline phosphatase level was significantly correlated with decreases in the function of the embolized right lobe of the liver. However, with regard to functional liver volume, pre-PVE portal pressure and alkaline phosphatase level were significantly correlated with decreased volume of the embolized right lobe of the liver, and LHL15, platelet count, and total cholesterol level were significantly correlated with increased volume of the nonembolized left lobe of the liver $(P<0.05)$.

Decision of operative indication in HCC patients with functionally borderline indication based on ${ }^{99 m}$ Tc-GSA liver scintigraphy

Table 4 shows the results of operative indication for major hepatectomy in patients with poor ICGR15. In four patients with LHL15 less than 0.9, the remnant functional volume was similar to the morphological volume. Major hepatectomy was avoided in all patients. In four patients with LHL15 greater than 0.9, the scheduled hepatectomy was contraindicated because of the results of ICGR15 by considering the morphological volumetry. By measuring functional 
volume, all four patients underwent scheduled major hepatectomy because the estimated resected volume was within permitted volumes, and postoperative hepatic failure was not observed in all. Histological examination did not show cirrhosis. Figure 7 shows an HCC patient with a dysfunctional right lobe of the liver for whom right hepatectomy was scheduled. ICGR15 was 27\% and permitted volume for resection was 31\%. After PVE, morphological volume of the right lobe of the liver was $56 \%$, which was beyond the permitted volume. However, LHL15 was 0.90 and functional volume of the right lobe of the liver was 31\% after PVE, which was in the upper limit of the permitted volume. Right hepatectomy accompanied by Hassab’s operation for gastric varices and combined resection of the right adrenal gland for HCC metastasis was performed. No postoperative complications were observed.

Comparison of survival after hepatectomy between the former and the latter period

Figure 8 shows the comparison of survival after hepatectomy in HCC patients between the former (1994-2003) and latter periods (since 2004). Disease-free and overall survival in the latter period was not significantly different from that in the former period

\section{Discussion}

${ }^{99 \mathrm{~m}}$ Tc-GSA liver scintigraphy is well known as a reliable test to assess hepatic functional reserve in patients with a diseased liver as it reveals live and active hepatic cells $(11,12,15,16)$. During ${ }^{99 \mathrm{~m}} \mathrm{Tc}$ GSA scintigraphy, both LHL15 $(25,26)$ and heart activity at 15 min by heart activity at 3 min (HH15) (26), or maximal removal rate $\left(R_{\max }\right)(15)$, are reliable as noninvasive parameters for evaluating hepatic functional reserve without blood sampling. Since 1996, our department has used ${ }^{99 \mathrm{~m}}$ Tc-GSA scintigraphy preoperatively in combination with ICGR15 and conventional liver function tests in patients with liver diseases. We have previously reported the clinical significance of ${ }^{99 \mathrm{~m}} \mathrm{Tc}$-GSA liver scintigraphy in patients with various types of liver impairment who underwent hepatic resection $(17,19,25)$. The results of this test are well correlated with other parameters of impaired hepatic function; however, the results of ${ }^{99 m}$ Tc-GSA liver scintigraphy sometimes do not correlate with the results of ICG testing in patients with a vascular shunt or icteric liver $(17,19,25)$. We have reported that ${ }^{99 \mathrm{~m}}$ Tc-GSA liver scintigraphy is more reliable for the evaluation of liver function compared with ICG testing in the case of hilar bile duct carcinoma with obstruction and for evaluation after PVE (17-19). To assess the latest treatment strategy for hepatectomy by considering the hepatic functional reserve, we focused on the assessment of ${ }^{99 m}$ Tc-GSA liver scintigraphy in only HCC patients in the present study. 
As stated above, we reviewed posthepatectomy morbidity in patients with various liver diseases who underwent hepatectomy in 2003 (25). On the basis of these results, we modified our strategy in 2004 by applying the ICGR15 test in addition to assessment of LHL15 of ${ }^{99 m}$ Tc-GSA liver scintigraphy, as well as prothrombin activity and serum hyaluronic acid level $(22,25)$. In borderline cases with impaired liver function, we aggressively coevaluated LHL15 as a reference for determining the indication of hepatectomy. ICGR15 test is a loading test to assess the metabolic function of the hepatic parenchyma and is a gold standard test in Japan for preoperative hepatic functional reserve, predicting liver failure and other forms of morbidity and mortality after hepatectomy $(5,10,20)$. We have accurately evaluated the operative indication by examining the ICGR15 test results, and postoperative morbidity and mortality have been markedly improved (25), although Western countries have still not applied this useful test at this stage. However, in some cases, such as in patients with bile duct carcinoma, intrahepatic shunt flow, or constitutional jaundice, the ICG test is not available. LHL15 results did not correlate with results of the ICGR15 test in some cases in the present series, and therefore LHL15 results may vary in some situations $(26,27)$. In the present series, five cases showed a lack of correlation between LHL15 and the conventional ICG test, as in our previous study (17). In two cases, LHL15 was relatively better than ICGR15. In these cases, function of the right lobe of the liver was affected by abscess formation or compression as a result of a large HCC. In such cases, the actual functioning region of the right lobe of the liver was reduced in comparison with the morphological region. When the opposite lobe of the liver (left lobe of the liver) was functioning well, as indicated by LHL15, the postoperative course was good. In cases in which LHL15 and ICGR15 data do not correlate, LHL15 might better reflect the actual regional function, which is reliable in predicting postoperative complications, as reported previously $(12,27,29,30)$. However, it was difficult to determine the extent of hepatectomy by assessing only LHL15 in the present study because of the narrow range of LHL15 distribution, although Kamohara et al. (31) reported the reliability of LHL15. In the present series, in some HCC patients with hepatic shunt flow based on radiological findings or those with the DubinJohnson syndrome, we applied the results of LHL15 and the postoperative outcome was uneventful. At this stage, ICGR15 is the gold standard test to decide the indication of hepatectomy and LHL15 is an auxiliary test to cover the limitations of the ICGR15 test. Some reports, including our previous report, have attempted to calculate the estimated data of ICGR15 by HH15 and LHL15 with conventional liver parameters (30). The formula for estimating ICGR15 using ${ }^{99 \mathrm{~m}} \mathrm{Tc}-\mathrm{GSA}$ liver scintigraphy is useful in cases with discrepant data. In the future, a comprehensive risk score or classification for postoperative morbidity using various hepatic functional parameters is necessary, as indicated in previous reports $(32,33)$. 
By applying ${ }^{99 \mathrm{~m}}$ Tc-GSA liver scintigraphy with the SPECT-CT fusion image, functional liver volume can be clinically evaluated by calculating the uptake volume of ${ }^{99 m}$ Tc-GSA $(11,13,16,19,34)$. On the basis of the amount of morphological liver volume, functional liver volume was seen to be well correlated. However, if diseased or impaired liver regions are present, the hepatic function of such regions would be decreased, based on our hypothesis $(18,19,34)$. In cases of hilar bile duct carcinoma, we have clarified the usefulness of ${ }^{99 \mathrm{~m}}$ Tc-GSA volumetry because evaluation of the ICG test was unreliable, whereas total bilirubin level was high (35). Further, diseased liver without drainage of the obstructive bile duct showed poor functioning (36). Application of volumetry by ${ }^{99 \mathrm{~m}} \mathrm{Tc}-\mathrm{GSA}$ scintigraphy might address the limitations of the ICG test, as this test can evaluate separated liver functions in any situation of background liver function (17). In cases of bile duct carcinoma, ${ }^{99 \mathrm{~m}} \mathrm{Tc}-\mathrm{GSA}$ volumetry is useful to evaluate separated liver functions in the embolized and nonembolized liver after PVE in comparison with morphological volumetry by conventional CT $(18,34,37)$. In HCC, portal vein tumor thrombosis of HCC and preoperative PVE in the main portal vein may deteriorate liver function because of decreased portal flow. In the present series, we examined the correlation between morphological and functional hepatic volumes of the right lobe of the liver after PVE in only six patients, which showed no tendency of correlation. Morphological and functional volumes of the right lobe of the liver showed a significant difference of $122 \mathrm{~cm}^{3}(-7.8 \%$; $=0.037)$. In the left lobe of the liver, however, the difference in morphological and functional volumes was not statistically significant. Decrease in portal flow may induce atrophy by apoptosis of hepatic cells but not necrosis or infarction (38), in which the functional mass detected by the asialoglycoprotein receptor might be decreased by hepatic injury, which cannot be detected by enhanced CT. In the present series, as expected, the diseased liver that decreased the portal flow showed a remarkable decrease in ${ }^{99 \mathrm{~m}}$ Tc- ${ }^{-99 \mathrm{~m}}$ Tc-GSA uptake, in which functional volume was decreased in comparison with the morphological volume, as in our pilot study $(17-19,21,22)$. In such cases, the indications for major hepatectomy might be suitable to decide markedly reduced functional volume. Examining ${ }^{99 \mathrm{~m}}$ Tc-GSA volumetry in HCC patients may be useful for evaluating the diseased and healthy liver. Sugai et al. (13) also reported that functional volume in the unembolized liver did not significantly increase but that the increase in liver uptake density was marked. Although functional shift in the unembolized liver could not have been prominently visible even by ${ }^{99 m}$ Tc-GSA scintigraphy, we speculate that there may be a greater potential for regeneration in the remnant liver after hepatectomy. Further, the safety of major hepatectomy following PVE might be confirmed, as the embolized right lobe of the liver lost much more hepatic function after PVE (27-29). In the present study, we presented a patient who failed to undergo scheduled hepatectomy after PVE because of worsened liver function due to portal hypertension after PVE. In this case, sequential 
alteration of LHL15 and functional liver volume provided useful information to evaluate the present status of liver function and to decide operative indications.

To our knowledge, reliable prediction of hypertrophy and atrophy by PVE has not been clarified yet. We previously examined the associated parameters of hepatic function to volumetric change by CT and ${ }^{99 \mathrm{~m}}$ Tc-GSA liver scintigraphy of embolized and nonembolized liver after PVE $(21,39)$. On the basis of these results, changes in functional volume were well correlated with other hepatic functions, and therefore it has been concluded that measuring the functional volume was useful for predicting the effect of PVE. In the present study, we performed a similar examination in HCC patients, and five parameters were significantly correlated with changes in functional volume but not with changes in morphological volume. At this stage, however, a predictive formula could not be established because no significant parameters were detected by multivariate analysis and the number of patients examined was small (data not shown). In the future, it will be necessary to develop a predictive classification.

As described above, we modified our strategy for deciding the operative indication. We examined patient outcomes in the short and long term between the former period and the latter period by applying our modified strategy. As described above, postoperative morbidity and mortality rates were significantly improved. With regard to patient survival after hepatectomy, various treatment modalities such as ablation or selective transarterial embolization have been applied recently and patient prognosis has improved in comparison with the previous period (40). Although patient prognosis tended to be improved in the latter period, these findings could not be clarified with statistical significance at this stage. Okabe et al. (41) recently reported that applying PVE for estimating functional volume by ${ }^{99 \mathrm{~m}}$ TcGSA liver scintigraphy provided better HCC patient prognosis after hepatectomy. On the basis of the precise functioning liver area, modification of treatment strategy may provide better patient prognosis. Although clinical evaluation by ${ }^{99 \mathrm{~m}} \mathrm{Tc}-\mathrm{GSA}$ liver scintigraphy is not frequently used in other countries (42), De Graaf et al. (43) recently attempted to apply a similar method of liver scintigraphy to evaluate separated hepatic function. Application of functional liver scintigraphy is a promising imaging test to determine liver functioning.

\section{Conclusion}

We have demonstrated the usefulness of measuring LHL15 and functional volume by ${ }^{99 \mathrm{~m}}$ Tc-GSA liver scintigraphy as a preoperative functional liver reserve in 67 HCC patients who underwent hepatectomy. LHL15 is useful as an auxiliary test of ICGR15 to decide the extent of hepatectomy. Further, the functional volume is apparently decreased in the liver of HCC patients with portal vein tumor thrombosis or embolization following PVE compared with that estimated by CT volumetry. To improve HCC patient outcome after hepatectomy in the early and the late period, adequate evaluation of 
preoperative functional liver reserve using a combination of reliable tests and related treatment criteria is necessary.

\section{References}

[1] Song TJ, Ip EW, Fong Y Hepatocellular carcinoma: current surgical management. Gastroenterology 2004;127:248-260.

[2] Poon RT, Fan ST Hepatectomy for hepatocellular carcinoma: patient selection and postoperative outcome. Liver Transpl 2004;10:39-45.

[3] Manizate F, Hiotis SP, Labow D, Roayaie S, Schwartz M Liver functional reserve estimation: state of the art and relevance to local treatments. Oncology 2010;78:131-134. [4] Imamura H, Sano K, Sugawara Y, Kokudo N, Makuuchi M Assessment of hepatic reserve for indication of hepatic resection: decision tree incorporating indocyanine green test. $J$ Hepatobiliary Pancreat Surg 2005;12:16-22.

[5] Miyagawa S, Makuuchi M, Kawasaki S, Kakazu T Criteria for safe hepatic resection. Am J Surg 1995;169:589-594.

[6] Yamanaka J, Saito S, Iimuro Y, Hirano T, Okada T, Kuroda N, et al. The impact of 3-D virtual hepatectomy simulation in living-donor liver transplantation. J Hepatobiliary Pancreat Surg 2006;13:363-369.

[7] Nakano H, Yoshida K, Takeuchi S, Kumada K, Yamaguchi M, Jaeck D Liver scintigraphy is useful for selecting candidates for preoperative transarterial chemoembolization among patients with hepatocellular carcinoma and chronic liver disease. Am J Surg 1999;178:385-389.

[8] Chen MF, Hwang TL, Hung CF Human liver regeneration after major hepatectomy: a study of liver volume by computed tomography. Ann Surg 1991;213:227-229. 
[9] Ogasawara K, Une Y, Nakajima Y, Uchino J The significance of measuring liver volume using computed tomographic images before and after hepatectomy. Surg Today 1995;25:43-48. [10] Kubota K, Makuuchi M, Kusaka K, Kobayashi T, Miki K, Hasegawa K, et al. Measurement of liver volume and hepatic functional reserve as a guide to decision-making in resectional surgery for hepatic tumors. Hepatology 1997; 26:1176-1181.

[11] Satoh K, Yamamoto Y, Nishiyama Y, Wakabayashi H, Ohkawa $\mathrm{M}^{99 \mathrm{~m}}$ Tc-GSA liver dynamic SPECT for the preoperative assessment of hepatectomy. Ann Nucl Med 2003;17:61-67. [12] Kwon AH, Matsui Y, Ha-Kawa SK, Kamiyama Y Functional hepatic volume measured by technetium-99m-galactosyl-human serum albumin liver scintigraphy: comparison between hepatocyte volume and liver volume by computed tomography. Am J Gastroenterol 2001;96:541546.

[13] Sugai Y, Komatani A, Hosoya T, Yamaguchi K Response to percutaneous transhepatic portal embolization: new proposed parameters by ${ }^{99 \mathrm{~m}}$ Tc-GSA SPECT and their usefulness in prognostic estimation after hepatectomy. J Nucl Med 2000;41:421-425.

[14] Wu J, Ishikawa N, Takeda T, Tanaka Y, Pan XQ, Sato M, et al. The functional hepatic volume assessed by ${ }^{99 m}$ Tc-GSA hepatic scintigraphy. Ann Nucl Med 1995;9:229-235. [15] Kwon AH, Ha-Kawa SK, Uetsuji S, Inoue T, Matsui Y, Kamiyama Y Preoperative determination of the surgical procedure for hepatectomy using technetium-99m-galactosyl human serum albumin $\left({ }^{99 \mathrm{~m}}\right.$ Tc-GSA) liver scintigraphy. Hepatology 1997;25:427-429. [16] Hwang EH, Taki J, Shuke N, Nakajima K, Kinuya S, Konishi S, et al. Preoperative assessment of residual hepatic functional reserve using ${ }^{99 \mathrm{~m}}$ Tc-DTPA-galactosyl-human serum albumin dynamic SPECT. J Nucl Med 1999;40:1644-1651. 
[17] Nanashima A, Yamaguchi H, Shibasaki S, Morino S, Ide N, Takeshita H, et al. Relationship between indocyanine green test and technetium-99m galactosyl serum albumin scintigraphy in patients scheduled for hepatectomy: clinical evaluation and patient outcome. Hepatol Res 2004;28:184-190.

[18] Nanashima A, Yamaguchi H, Shibasaki S, Morino S, Ide N, Takeshita H, et al. Relationship between CT volumetry and functional liver volume using technetium-99m galactosyl serum albumin scintigraphy in patients undergoing preoperative portal vein embolization before major hepatectomy: a preliminary study. Dig Dis Sci 2006;51:1190-1195. [19] Nanashima A, Sumida Y, Abo T, Sakamoto I, Ogawa Y, Sawai T, et al. Usefulness of measuring hepatic functional volume using technetium-99m galactosyl serum albumin scintigraphy in bile duct carcinoma: report of two cases. J Hepatobiliary Pancreat Surg 2009;16:386-393.

[20] Takasaki T, Kobayashi S, Suzuki S, Muto H, Marada M, Yamana Y, et al. Predetermining postoperative hepatic function for hepatectomies. Int Surg 1980;65:309-313. [21] Nanashima A, Sumida Y, Shibasaki S, Takeshita H, Hidaka S, Sawai T, et al. Parameters associated with changes in liver volume in patients undergoing portal vein embolization. J Surg Res 2006;133:95-101.

[22] Nanashima A, Yamaguchi H, Shibasaki S, Sawai T, Yamaguchi E, Yasutake T, et al. Measurement of serum hyaluronic acid level during the perioperative period of liver resection for evaluation of functional liver reserve. J Gastroenterol Hepatol 2001;16:1158-1163.

[23] Koizumi K, Uchiyama G, Arai T, Ainoda T, Yoda Y A new liver functional study using Tc-99m DTPA-galactosyl human serum albumin: evaluation of the validity of several functional parameters. Ann Nucl Med 1992;6:83-87. 
[24] Shikada Y, Matsumata T, Suehiro T, Sugimachi K Hepatocellular carcinoma in a case of Dubin-Johnson syndrome treated successfully with a central bilateral segmentectomy. Hepatogastroenterology 2004;51:833-836.

[25] Nanashima A, Tobinaga S, Abo T, Nonaka T, Takeshita H, Hidaka S, et al. Reducing the incidence of post-hepatectomy hepatic complications by preoperatively applying parameters predictive of liver function. J Hepatobiliary Pancreat Sci 2010;17:871-878.

[26] Kim YK, Nakano H, Yamaguchi Y, Kumada K, Takeuchi S, Kitamura N, et al. Prediction of postoperative decompensated liver function by technetium-99m-labeled-galactosylhuman serum albumin liver scintigraphy in patients with hepatocellular carcinoma complicating chronic liver disease. Br J Surg 1997;84:793-796.

[27] Kwon AH, Ha-Kawa SK, Uetsuji H, Kamiyama Y, Tanaka Y Use of technetium 99m diethylenetriaminepentaacetic acid-galactosyl human serum albumin liver scintigraphy in the evaluation of preoperative and postoperative hepatic functional reserve for hepatectomy. Surgery 1995;117:429-434.

[28] Kokudo N, Vera DR, Tada K, Koizumi M, Seki M, Matsubara T, et al. Predictors of successful hepatic resection: prognostic usefulness of hepatic asialoglycoprotein receptor analysis. World J Surg 2002;26:1342-1347.

[29] Kaibori M, Ha-Kawa SK, Ishizaki M, Matsui K, Saito T, Kwon AH, et al. HA/GSA$\mathrm{R}_{\max }$ ratio as a predictor of postoperative liver failure. World J Surg 2008;32:2410-2418.

[30] Kawamura H, Kamiyama T, Nakagawa T, Nakanishi K, Yokoo H, Tahara M, et al. Preoperative evaluation of hepatic functional reserve by converted ICGR15 calculated from TcGSA scintigraphy. J Gastroenterol Hepatol 2008;23:1235-1241. 
[31] Kamohara Y, Takatsuki M, Hidaka M, Soyama A, Kanematsu T, Eguchi S ${ }^{99 m}$ TcGalactosyl sialyl albumin (GSA) scintigram adjusts hepatic resection range in ICG based estimation. Hepatogastroenterology 2011;58:2058-2061.

[32] Andres A, Toso C, Moldovan B, Schiffer E, Rubbia-Brandt L, Terraz S, et al. Complications of elective liver resections in a center with low mortality: a simple score to predict morbidity. Arch Surg 2011;146:1246-1252.

[33] Paugam-Burtz C, Janny S, Delefosse D, Dahmani S, Dondero F, Mantz J, et al. Prospective validation of the 'fifty-fifty' criteria as an early and accurate predictor of death after liver resection in intensive care unit patients. Ann Surg 2009;249:124-128.

[34] Beppu T, Hayashi H, Okabe H, Masuda T, Mima K, Otao R, et al. Liver functional volumetry for portal vein embolization using a newly developed ${ }^{99 \mathrm{~m}}$ Tc-galactosyl human serum albumin scintigraphy SPECT-computed tomography fusion system. J Gastroenterol 2011;46:938943.

[35] Fan ST, Wang QS, Lo CM, Tam YuKW, Lai EC, Wong J Evaluation of indocyanine green retention and aminopyrine breath tests in patients with malignant biliary obstruction. Aust N Z J Surg 1994;64:759-762.

[36] Nagino M, Nimura Y, Kamiya J, Kondo S, Uesaka K, Kin Y, et al. Changes in hepatic lobe volume in biliary tract cancer patients after right portal vein embolization. Hepatology 1995;21:434-439.

[37] Nishiyama Y, Yamamoto Y, Hino I, Satoh K, Wakabayashi H, Ohkawa M ${ }^{99 m}$ Tc galactosyl human serum albumin liver dynamic SPET for pre-operative assessment of hepatectomy in relation to percutaneous transhepatic portal embolization. Nucl Med Commun 2003;24:809-817. 
[38] Hwang S, Lee SG, Ko GY, Kim BS, Sung KB, Kim MH, et al. Sequential preoperative ipsilateral hepatic vein embolization after portal vein embolization to induce further liver regeneration in patients with hepatobiliary malignancy. Ann Surg 2009;249:608-616.

[39] Nanashima A, Abo T, Tobinaga S, Nonaka T, Fukuoka H, Hidaka S, et al. Prediction of indocyanine green retention rate at 15 min by correlated liver function parameters before hepatectomy. J Surg Res 2011;169:119-125.

[40] Sharma R, Gibbs JF Recent advances in the management of primary hepatic tumors refinement of surgical techniques and effect on outcome. J Surg Oncol 2010;101:745-754. [41] Okabe H, Beppu T, Ishiko T, Masuda T, Hayashi H, Otao R, et al. Preoperative portal vein embolization (PVE) for patients with hepatocellular carcinoma can improve resectability and may improve disease-free survival. J Surg Oncol 2011;104:641-646.

[42] Schneider PD Preoperative assessment of liver function. Surg Clin North Am 2004;84:355373.

[43] de Graaf W, van Lienden KP, van Gulik TM, Bennink RJ (99m)Tc-mebrofenin hepatobiliary scintigraphy with SPECT for the assessment of hepatic function and liver functional volume before partial hepatectomy. J Nucl Med 2010;51:229-236.

Fig. 1Volumetric measurement of the liver through SPECT images for calculating functional hepatic volume by ${ }^{99 \mathrm{~m}}$ Tc-GSA liver scintigraphy. ROIs for measuring functional liver volume using the workstation software were identified and sectional volumetric measurements were recorded. Liver uptake in each sector is shown by a color image. ${ }^{99 \mathrm{~m}}$ Tc-GSA, technetium-99m galactosyl human serum albumin; SPECT, single-photon emission computed tomography.

Fig. 2Linear correlation between ICGR15 and LHL15 in HCC patients. The circle with an actual line shows patients with better LHL15 in comparison with ICGR15, and the circle with the dotted line shows patients with worse LHL15 in comparison with ICGR15. HCC, hepatocellular carcinoma; ICGR15, indocyanine green retention rate at $15 \mathrm{~min}$; LHL15, liver uptake ratio at $15 \mathrm{~min}$. 
Fig. 3Two representative HCC cases showing decreased function on GSA liver scintigraphy. (a) A case with good uptake of ${ }^{99 \mathrm{~m}} \mathrm{Tc}$-GSA in the left lobe of the liver and (b) a case with poor uptake. ${ }^{99 \mathrm{~m}}$ TcGSA, technetium-99m galactosyl human serum albumin; HCC, hepatocellular carcinoma.

Fig. 4Relationship between LHL15, extent of hepatectomy, and postoperative morbidity. LHL15, liver uptake ratio at $15 \mathrm{~min}$.

Fig. 5Relationship between morphological and functional hepatic volume in each hemiliver. CT, computed tomography.

Fig. 6(A) Difference in morphological findings and functional hepatic uptake between the right and left lobes of the liver of HCC patients with major portal vein tumor thrombus (arrow). (B) A representative case of an HCC patient in whom we abandoned hepatectomy after preoperative sequential arterial and portal vein embolization. HCC, hepatocellular carcinoma; PVE, portal vein embolization. TAE, transarterial embolization. a) image of HCC by computed tomography, b)image by ${ }^{99 \mathrm{~m}}$ Tc-GSA before PVE, c) image by ${ }^{99 \mathrm{~m}} \mathrm{Tc}-\mathrm{GSA}$ at 2 weeks after arterial and portal embolization, d) image of HCC by computed tomography after arterial and portal embolization, e) image by ${ }^{99 \mathrm{~m}} \mathrm{Tc}-\mathrm{GSA}$ at 4 weeks and f) image by ${ }^{99 \mathrm{~m}}$ Tc-GSA at day 78 .

Fig. 7A representative case with borderline liver function for indication of hepatectomy in whom we successfully performed right hepatectomy by evaluating the functional liver volume.

Fig. 8Comparison of disease-free and overall survival rates (DFS and OAS, respectively) after hepatectomy between the former and latter periods in HCC patients. HCC, hepatocellular carcinoma. Table 1Clinicopathological findings and posthepatectomy outcomes in five HCC patients with divergence of correlation between ICGR15 and LHL15

\begin{tabular}{|c|c|c|c|c|c|c|c|c|c|}
\hline & Age, sex & $\begin{array}{l}\text { Backgro } \\
\text { und } \\
\text { Disease }\end{array}$ & $\begin{array}{c}\text { Hepatec } \\
\text { tomy }\end{array}$ & $\begin{array}{c}\text { ICGR15 } \\
\text { (\%) }\end{array}$ & LHL15 & Staging & Grading & $\begin{array}{l}\text { Complic } \\
\text { ations }\end{array}$ & $\begin{array}{c}\text { Hospital } \\
\text { stay } \\
\text { (days) }\end{array}$ \\
\hline 1 & 79, male & $\begin{array}{l}\text { Liver } \\
\text { abscess } \\
\text { in the } \\
\text { right } \\
\text { lobe of } \\
\text { the liver }\end{array}$ & $\begin{array}{l}\text { Extende } \\
\text { d right } \\
\text { hepatect } \\
\text { omy }\end{array}$ & 29 & 0.96 & 2 & 2 & Nil & 15 \\
\hline 2 & 72, male & $\begin{array}{l}\text { Large } \\
\text { HCC } \\
\text { occupyi } \\
\text { ng the } \\
\text { right }\end{array}$ & $\begin{array}{l}\text { Right } \\
\text { trisectio } \\
\text { nectomy }\end{array}$ & 39 & 0.93 & 1 & 2 & $\begin{array}{l}\text { Hyperbi } \\
\text { lirubine } \\
\text { mia }\end{array}$ & 28 \\
\hline
\end{tabular}




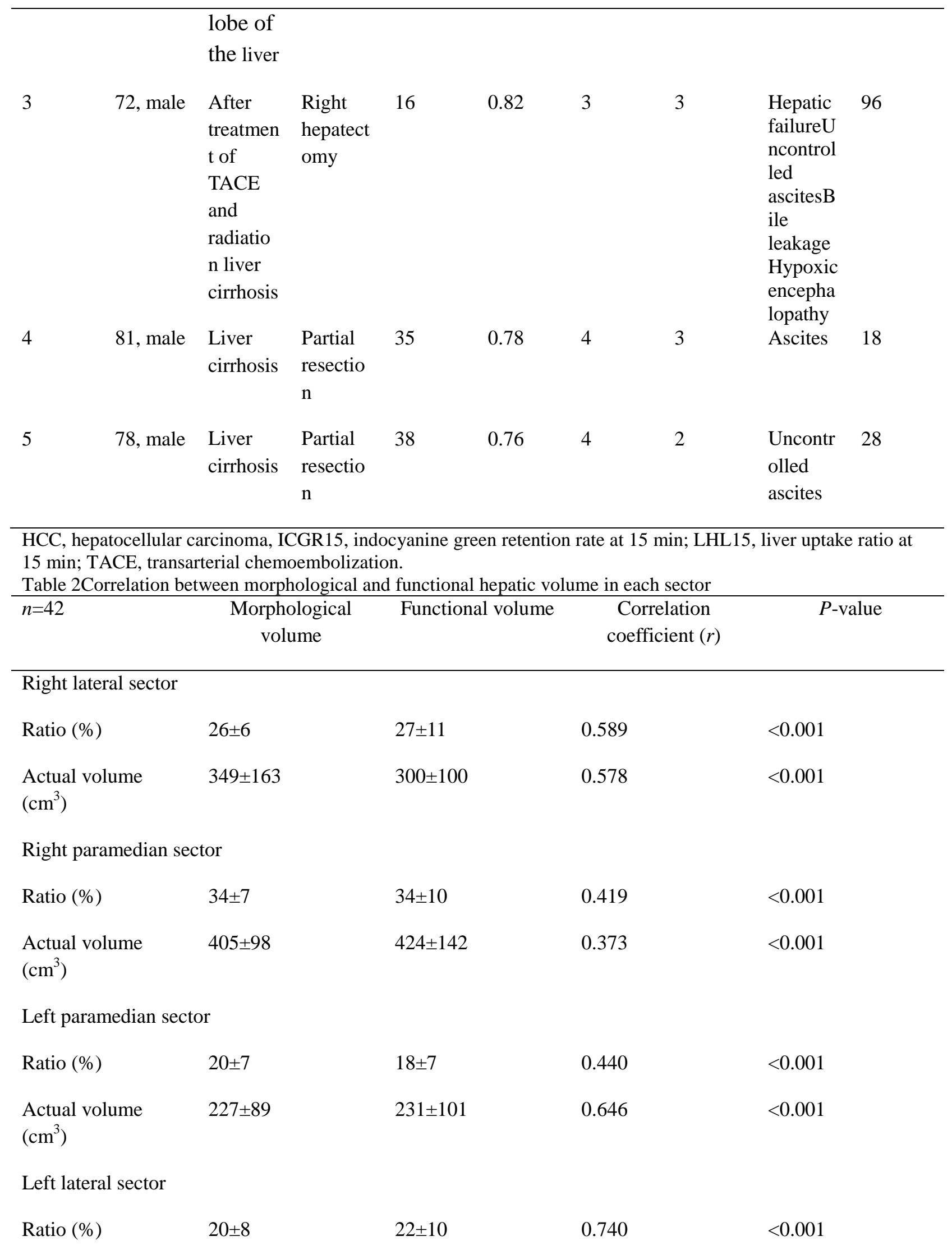


Nanashima et al., Page 20
Actual volume
$235 \pm 92$
$267 \pm 112$
0.737
$<0.001$
$\left(\mathrm{cm}^{3}\right)$

Table 3Correlation between parameters and changes in volumetric parameter after portal vein embolization

\begin{tabular}{|c|c|c|c|c|}
\hline & \multicolumn{4}{|c|}{$\gamma$} \\
\hline & \multicolumn{2}{|c|}{ CT volumetry } & \multicolumn{2}{|c|}{ RI volumetry } \\
\hline & $\begin{array}{c}\text { Decrease in } \\
\text { embolized liver } \\
\text { volume }\left(\mathrm{cm}^{3}\right)\end{array}$ & $\begin{array}{c}\text { Increase in } \\
\text { nonembolized liver } \\
\text { volume }\left(\mathrm{cm}^{3}\right)\end{array}$ & $\begin{array}{c}\text { Decrease in } \\
\text { embolized liver } \\
\left(\mathrm{cm}^{3}\right)\end{array}$ & $\begin{array}{c}\text { Increase in } \\
\text { nonembolized liver } \\
\left(\mathrm{cm}^{3}\right)\end{array}$ \\
\hline Age & 0.446 & 0.441 & 0.232 & -0.023 \\
\hline $\begin{array}{l}\text { Pre-PVE portal } \\
\text { pressure (mmHg) }\end{array}$ & 0.002 & -0.012 & $-0.498^{*}$ & -0.001 \\
\hline $\begin{array}{l}\text { Post-PVE portal } \\
\text { pressure (mmHg) }\end{array}$ & 0.235 & -0.338 & -0.332 & 0.178 \\
\hline $\begin{array}{l}\text { Hyaluronate } \\
(\mathrm{ng} / \mathrm{ml})\end{array}$ & 0.038 & -0.035 & -0.468 & 0.302 \\
\hline ICGR15 (\%) & 0.434 & 0.071 & -0.408 & 0.003 \\
\hline LHL15 & 0.322 & 0.041 & 0.005 & $0.606^{*}$ \\
\hline $\begin{array}{l}\text { Total bilirubin } \\
(\mathrm{mg} / \mathrm{dl})\end{array}$ & -0.001 & 0.072 & 0.111 & 0.227 \\
\hline $\begin{array}{l}\text { Alanine } \\
\text { aminotransferase } \\
(\mathrm{IU} / \mathrm{l})\end{array}$ & 0.533 & 0.413 & 0.099 & 0.333 \\
\hline $\begin{array}{l}\text { Prothrombin } \\
\text { activity (\%) }\end{array}$ & -0.120 & 0.126 & -0.262 & 0.308 \\
\hline $\begin{array}{l}\text { Platelet count } \\
\left(/ \mathrm{mm}^{3}\right)\end{array}$ & 0.389 & 0.316 & -0.389 & $0.459^{*}$ \\
\hline Albumin (g/dl) & -0.099 & 0.113 & 0.367 & 0.103 \\
\hline $\begin{array}{l}\text { Alkaline } \\
\text { phosphatase (IU/l) }\end{array}$ & $-0.416^{*}$ & 0.132 & $-0.478^{*}$ & 0.166 \\
\hline $\begin{array}{l}\text { Total cholesterol } \\
(\mathrm{mg} / \mathrm{dl})\end{array}$ & 0.334 & 0.080 & -0.167 & $0.484^{*}$ \\
\hline
\end{tabular}

CT, computed tomography; ICGR15, indocyanine green retention rate at $15 \mathrm{~min}$; LHL15, liver uptake ratio at 15 min; PVE, portal vein embolization. *:p<0.05 
Table 4Borderline HCC cases evaluated by conventional indication with additional evaluation by ${ }^{99 m}$ Tc-GSA liver scintigraphy

\begin{tabular}{|c|c|c|c|c|c|c|c|}
\hline $\begin{array}{c}\text { Backgrou } \\
\text { nd liver }\end{array}$ & $\begin{array}{c}\text { ICGR15 } \\
\text { (\%) }\end{array}$ & LHL15 & $\begin{array}{c}\text { Total } \\
\text { bilirubin } \\
\text { (mg/dl) }\end{array}$ & $\begin{array}{c}\text { Estimated } \\
\text { hepatecto } \\
\text { my }\end{array}$ & $\begin{array}{l}\text { Estimated } \\
\text { morpholo } \\
\text { gical } \\
\text { volume } \\
\text { of } \\
\text { resected } \\
\text { liver (\%) }\end{array}$ & $\begin{array}{l}\text { Estimated } \\
\text { functiona } \\
\text { l volume } \\
\text { of } \\
\text { resected } \\
\text { liver (\%) }\end{array}$ & $\begin{array}{l}\text { Hepatic } \\
\text { failure }\end{array}$ \\
\hline
\end{tabular}

\begin{tabular}{|c|c|c|c|c|c|c|}
\hline \multicolumn{7}{|c|}{ Not resected $(n=4)$} \\
\hline Cirrhosis & 44 & 0.89 & 0.8 & $\begin{array}{l}\text { Right } \\
\text { hepatecto } \\
\text { my }\end{array}$ & 32 & 20 \\
\hline Cirrhosis & 26 & 0.76 & 0.9 & $\begin{array}{l}\text { Right } \\
\text { hepatecto } \\
\text { my }\end{array}$ & 59 & 49 \\
\hline Cirrhosis & 27 & 0.88 & 1.3 & $\begin{array}{l}\text { Right } \\
\text { hepatecto } \\
\text { my }\end{array}$ & 61 & 55 \\
\hline Cirrhosis & 51 & 0.85 & 1.1 & $\begin{array}{l}\text { Right } \\
\text { hepatecto } \\
\text { my }\end{array}$ & 68 & 65 \\
\hline
\end{tabular}

Resected due to results by GSA liver scintigraphy $(n=4)$

\begin{tabular}{|c|c|c|c|c|c|c|c|}
\hline $\begin{array}{l}\text { Chronic } \\
\text { hepatitis }\end{array}$ & 15 & 0.92 & 0.6 & $\begin{array}{l}\text { Right } \\
\text { hepatecto } \\
\text { my }\end{array}$ & 32 & 11 & None \\
\hline $\begin{array}{l}\text { Chronic } \\
\text { hepatitis }\end{array}$ & 27 & 0.89 & 0.6 & $\begin{array}{l}\text { Right } \\
\text { hepatecto } \\
\text { my and } \\
\text { Hassab’s } \\
\text { operation }\end{array}$ & 56 & 31 & None \\
\hline $\begin{array}{l}\text { Chronic } \\
\text { hepatitis }\end{array}$ & 31 & 0.92 & 1.3 & $\begin{array}{l}\text { Posterior } \\
\text { sectionect } \\
\text { omy }\end{array}$ & 34 & 12 & None \\
\hline $\begin{array}{l}\text { Chronic } \\
\text { hepatitis }\end{array}$ & 18 & 0.95 & 0.6 & $\begin{array}{l}\text { Right } \\
\text { hepatecto } \\
\text { my }\end{array}$ & 60 & 43 & None \\
\hline
\end{tabular}

\footnotetext{
${ }^{99 m}$ Tc-GSA, technetium-99m galactosyl human serum albumin; HCC, hepatocelluar carcinoma; ICGR15, indocyanine green retention rate at $15 \mathrm{~min}$; LHL15, liver uptake ratio at $15 \mathrm{~min}$.
} 
Fig.1

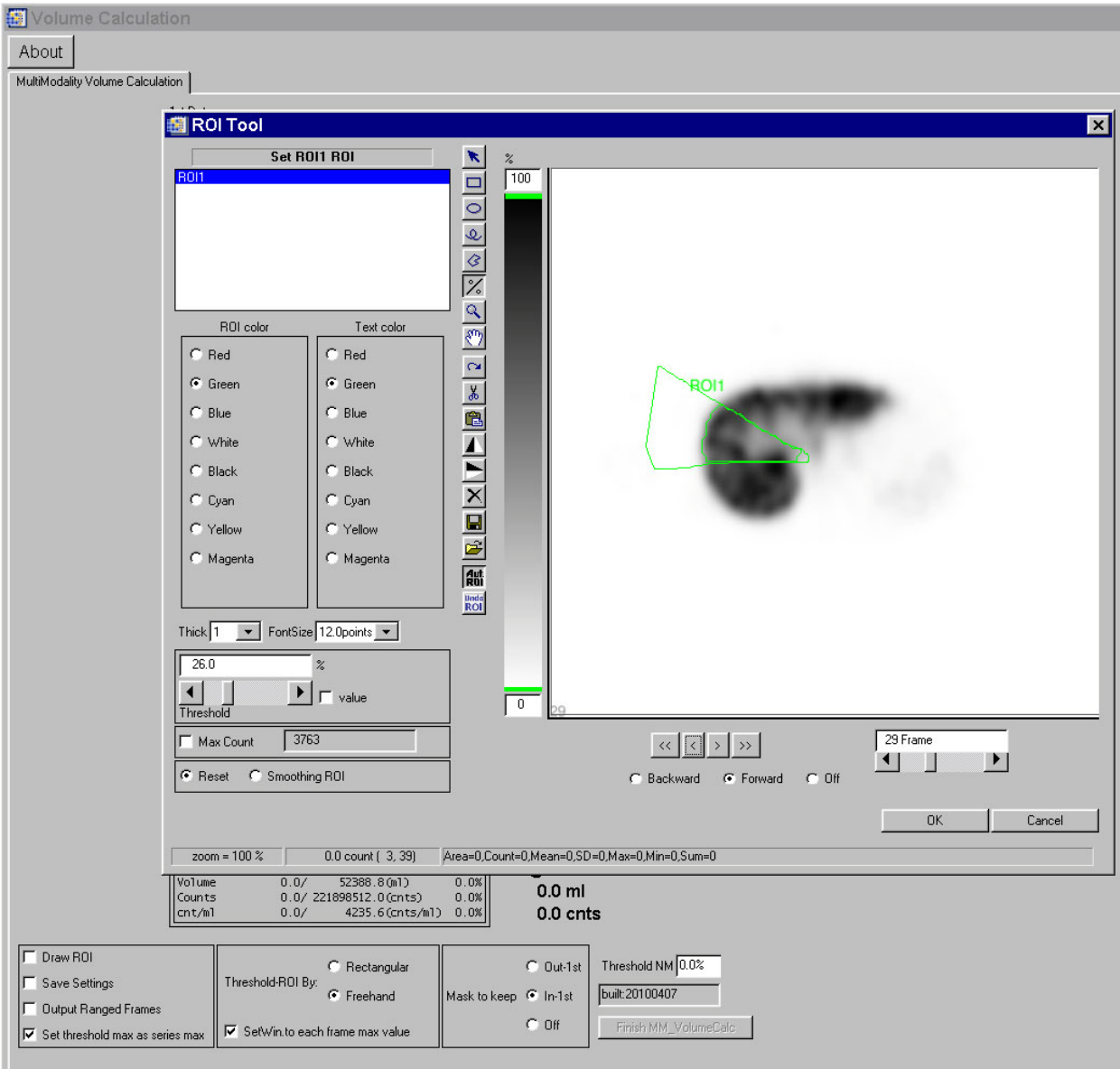

posterior sector

anterior sector

median sector

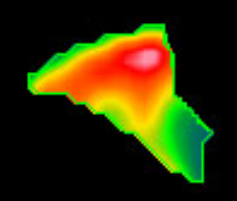

lateral sector

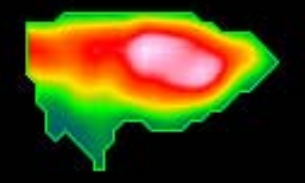


Fig.2

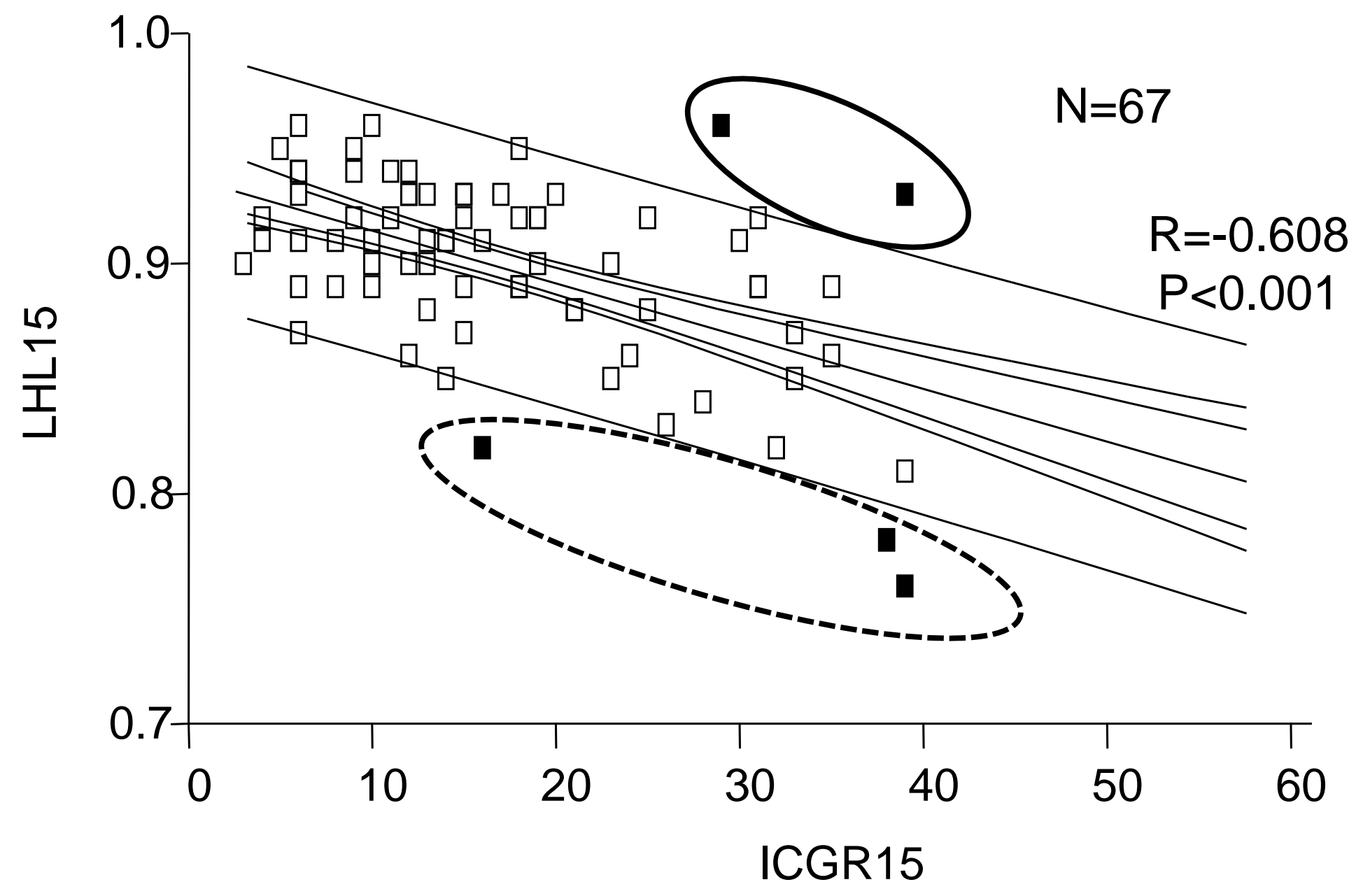


Fig.3a
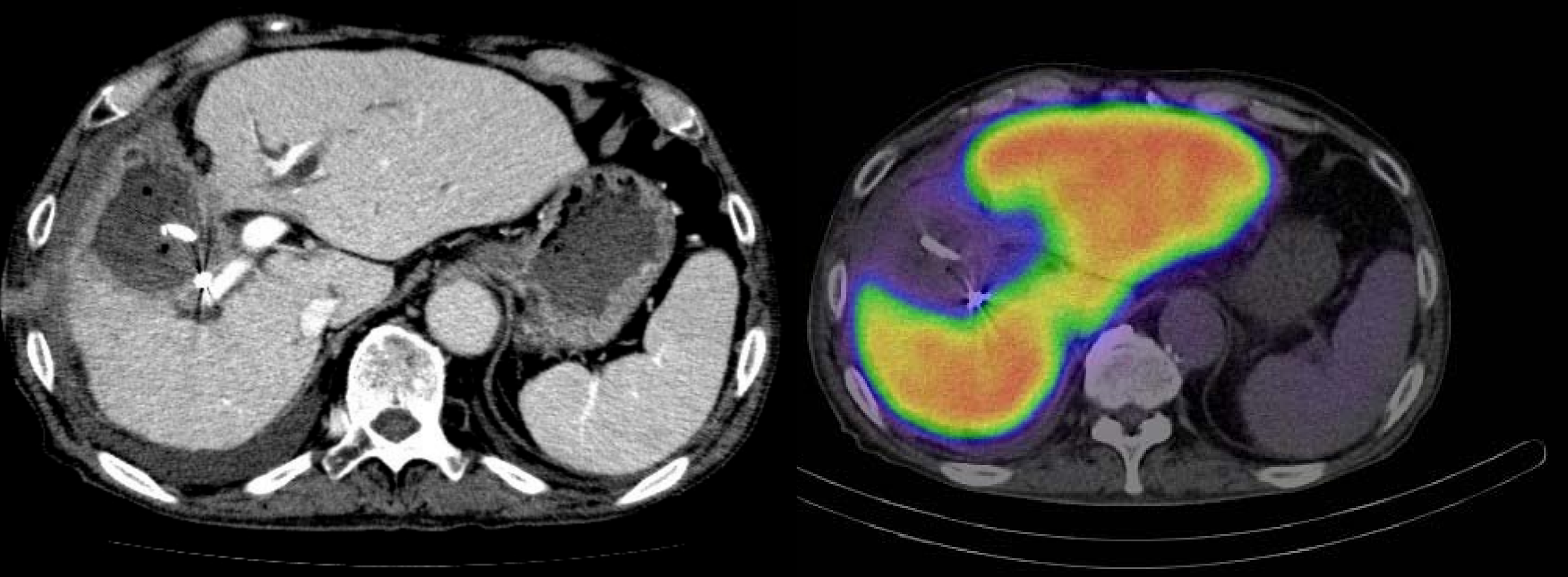
Fig.3b
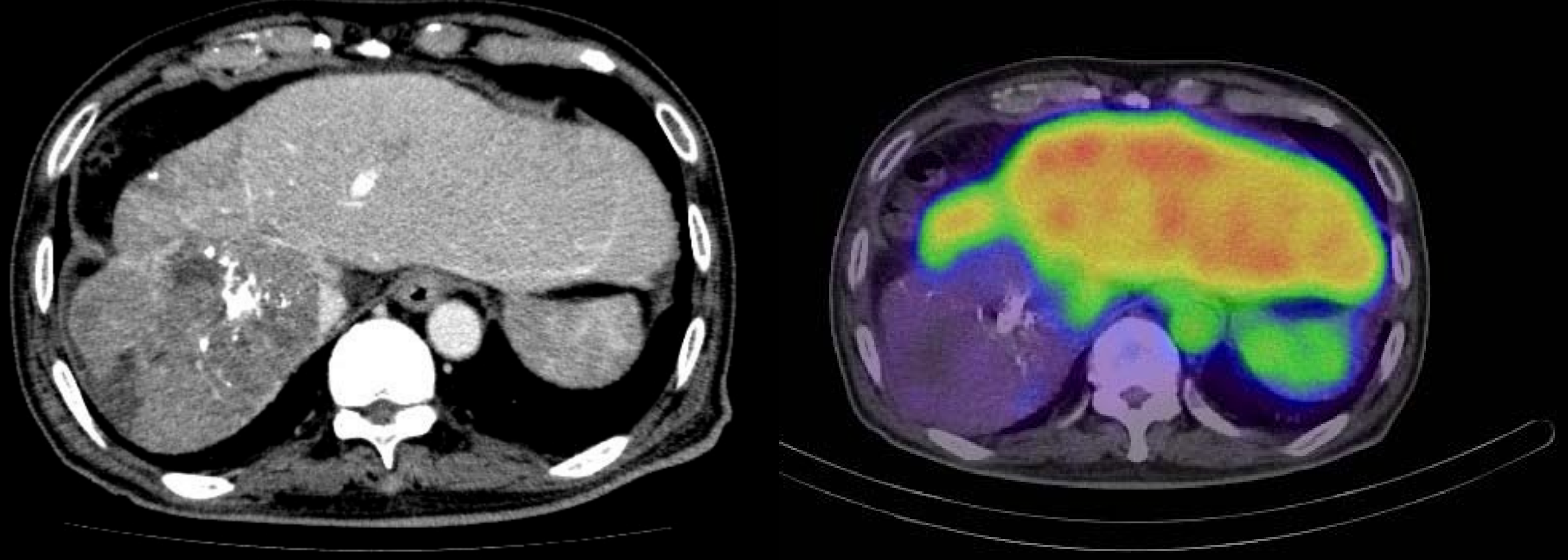
Fig. 4

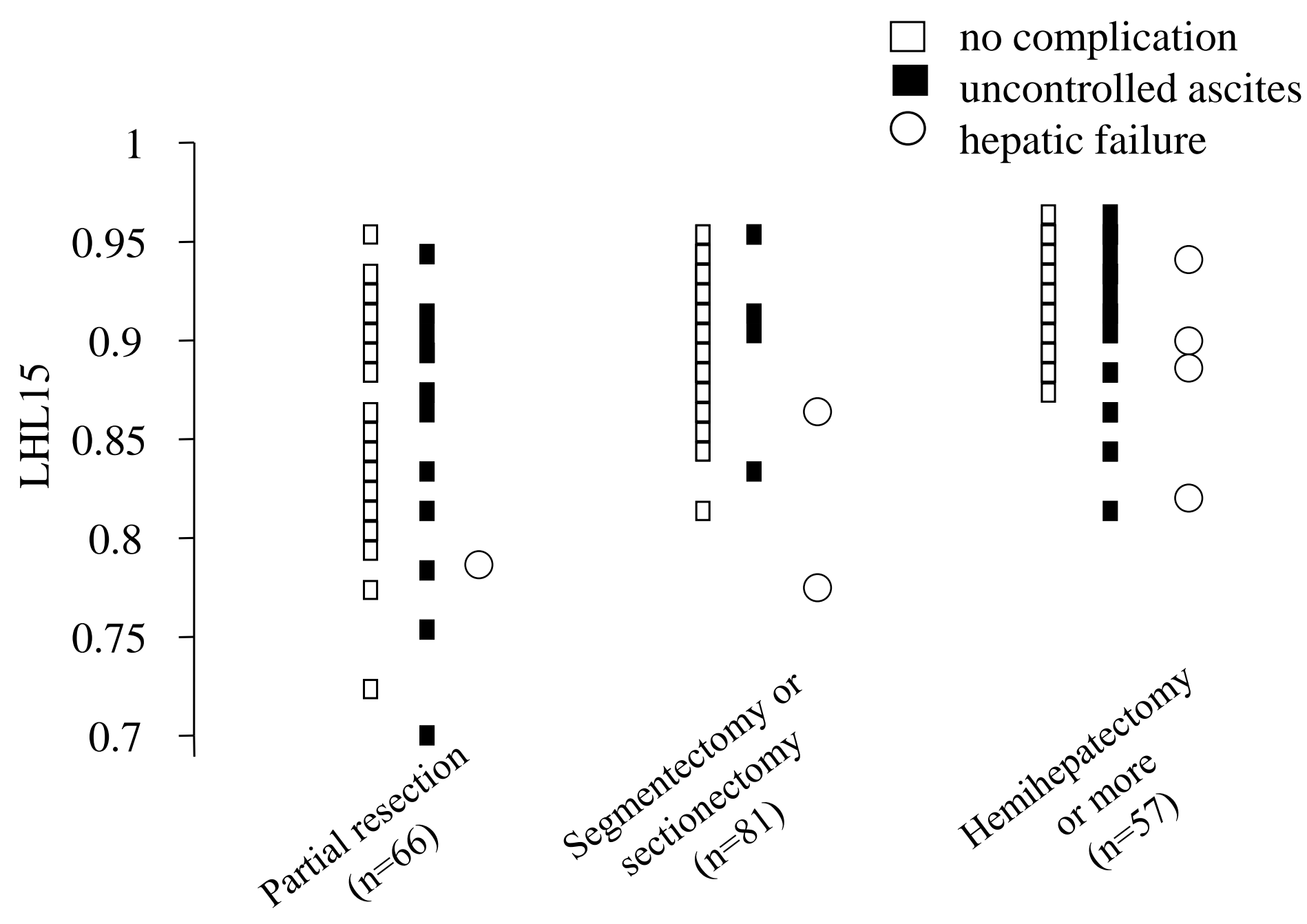


Fig. 5
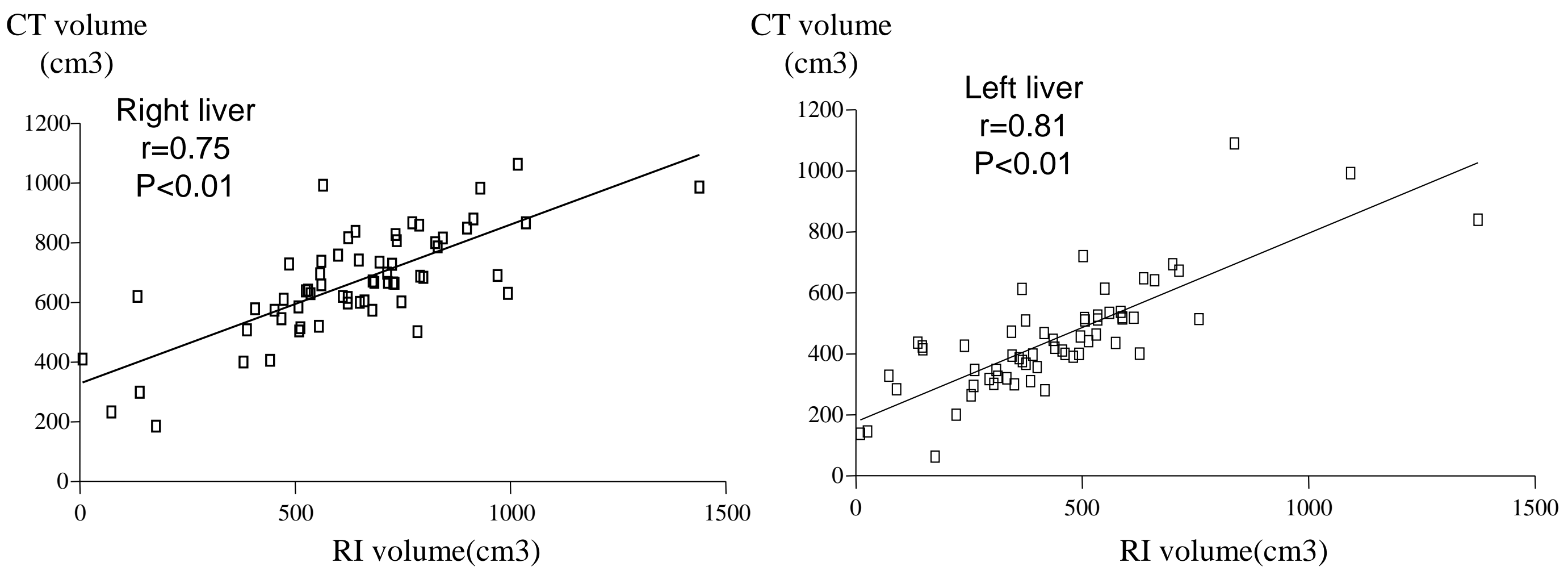
Fig. 6a

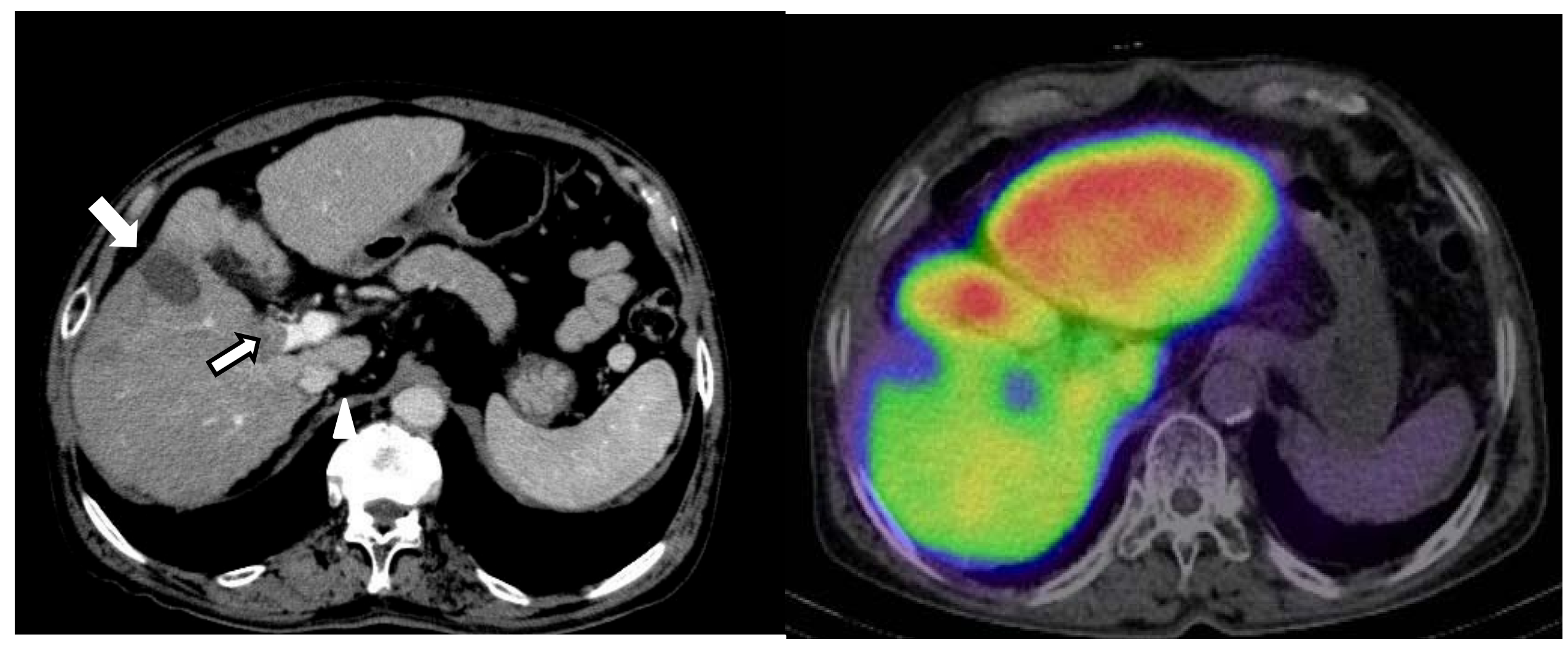


Fig. 6b

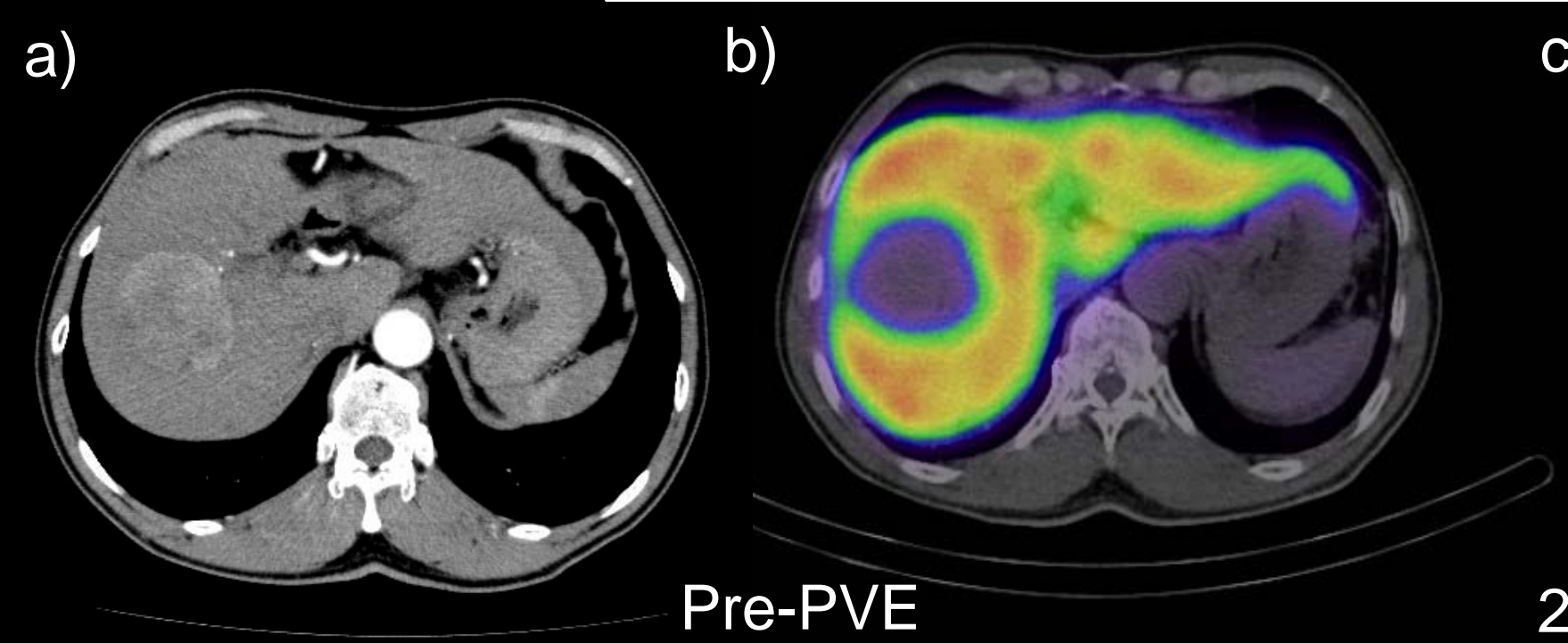

c)

d)

e)

2 weeks after TAE+PVE

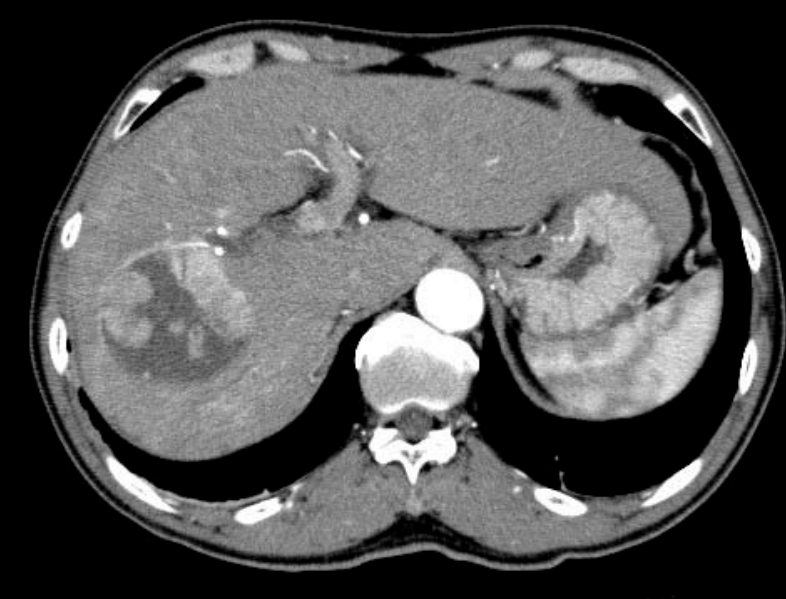

f)
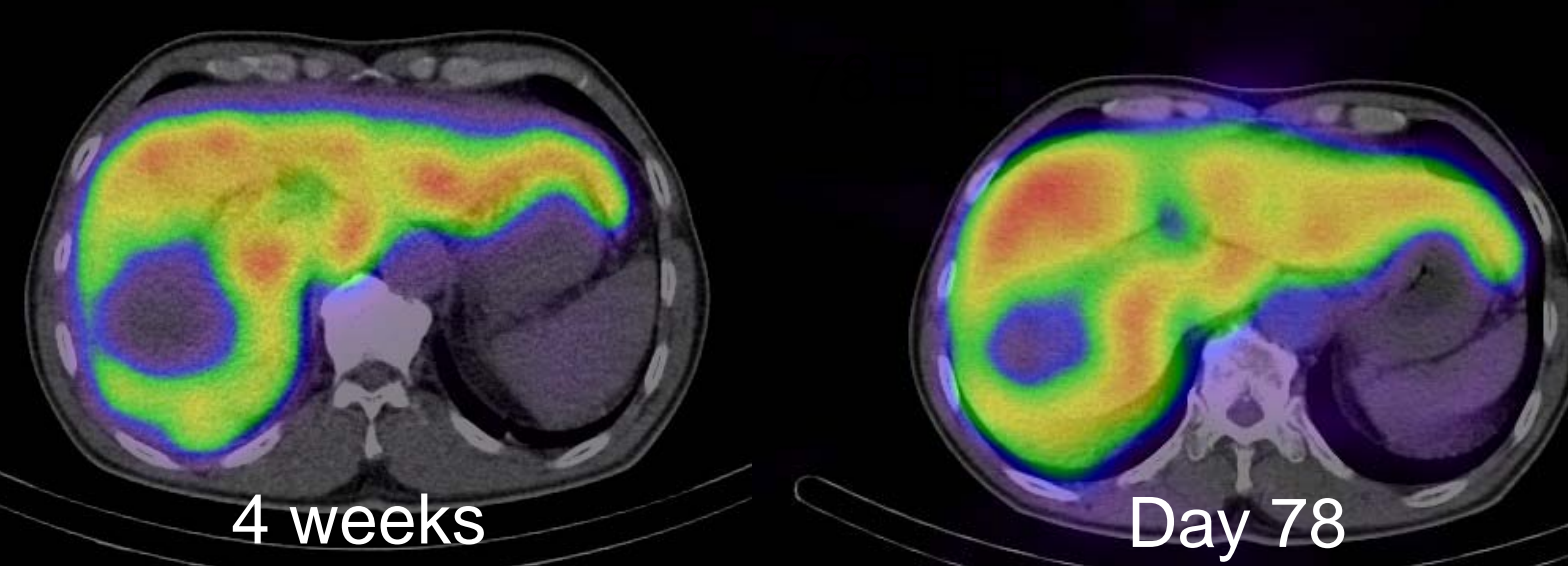
Fig. 7
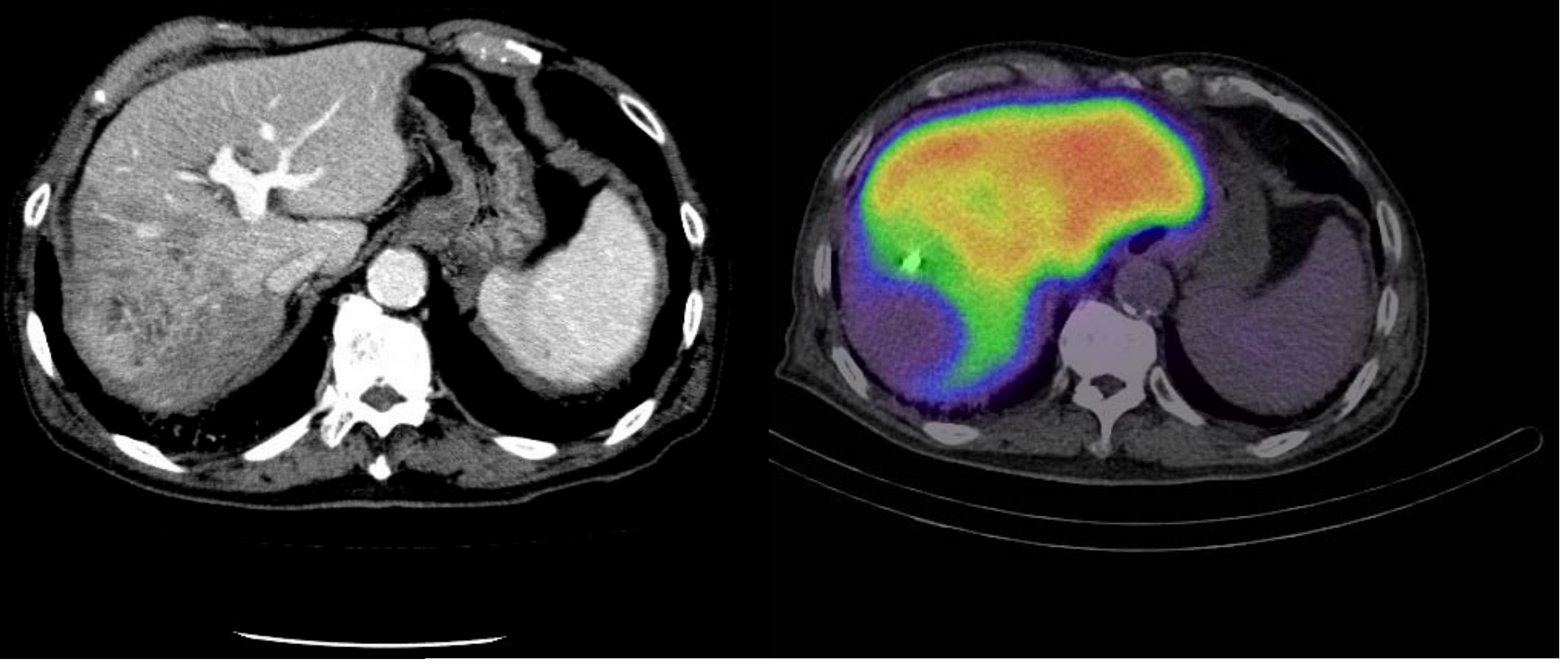
Fig. 8
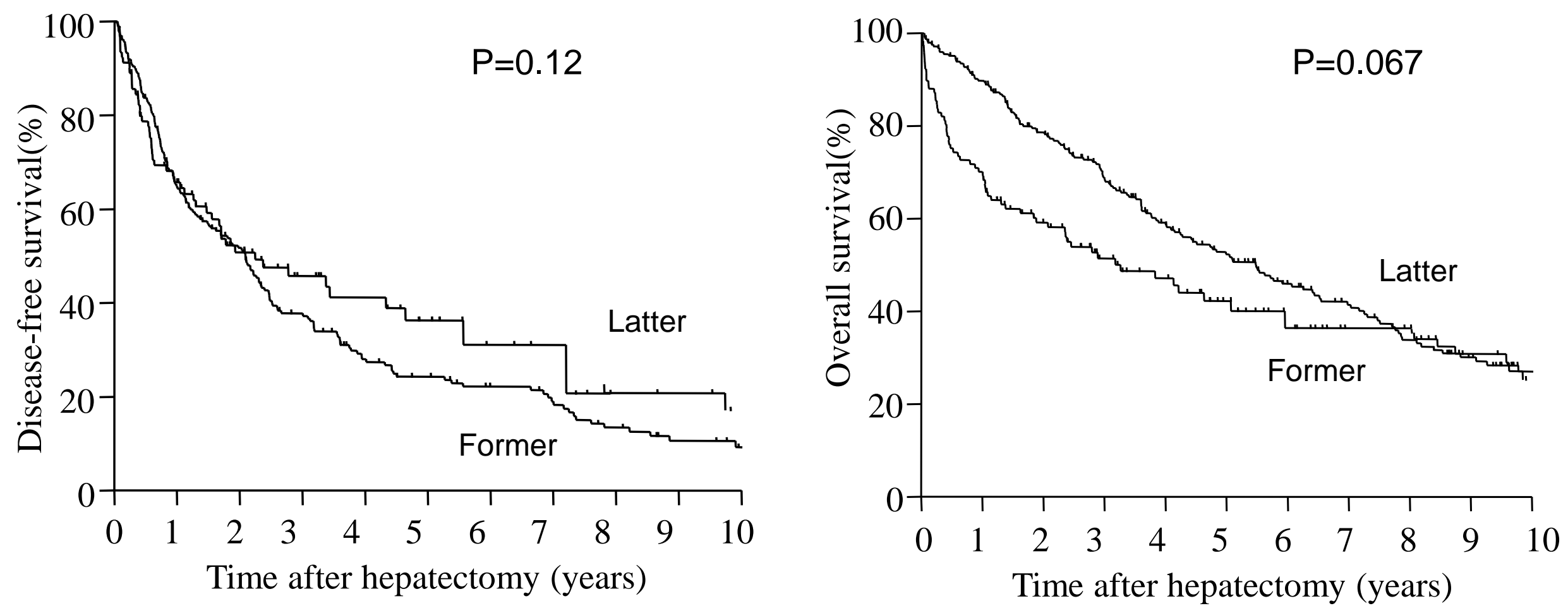

DFS

Former period Later period
1- 3- 5- 10years

$\begin{array}{llll}65 & 39 & 42 & 11 \%\end{array}$

$\begin{array}{llll}67 & 46 & 36 & 21 \%\end{array}$
OAS

Former period $51 \quad 42 \quad 36 \%$

Latter period $\quad 69 \quad 51 \quad 27 \%$ 